\title{
An Approach to Design and Develop Convertible Women's Wear Using Eco Friendly Textiles
}

\author{
Lakshana $S^{1}$ and Mariyam Adnan ${ }^{2}$ \\ \{lakshanasenthil897@gmail.com ${ }^{1}$, mag.afd@psgtech.ac.in ${ }^{2}$ \} \\ ${ }^{1}$ PG Student, Assistant Professor ${ }^{2}$, Department of Apparel and Fashion Design, PSG College of Technology, \\ Coimbatore
}

\begin{abstract}
A highly debated and increasingly covered topic today is sustainability. Many clothing companies are transforming their approach in business and improvising their supply chains to reduce the overall environmental impact and improving social conditions in factories. There are many methods to make sustainable garments, out of which one of them is to make convertible garments. They have the potential to change design and function which allows consumers to keep and use garments in a variety of ways. Transformable or convertible apparel offers functional and/or alternative aesthetic styles through various methods, which is considered a sustainable option in the fashion industry to reduce excess clothing consumption. In this paper, a convertible women's clothing collection is developed. It also analyses consumer preferences and intention to buy the clothing through a survey collected from a convenient sample of 50 respondents. The results of this study will benefit apparel designers, merchandisers, and retailers in developing and promoting convertible dresses.
\end{abstract}

Keywords: Sustainability, Convertible clothing, and Clothing impacts, Eco-friendly

\section{Introduction}

Sustainable fashion is an approach towards sourcing and designing clothing which maximizes the benefits to the industry and society. It should also at the same time reduce the impact on the environment. The meaning of ethics is something that is morally right and acceptable. Ethical and sustainable fashion does not start from manufacturing clothes alone; in fact it starts from the cotton fields and ends in the consumer's wardrobe. Today, sustainability has become a way of doing business rather than just a concept. Many brands and companies have now embraced the concept of sustainability and implemented it in their business. These companies have understood that integrating social and environmental issues with business will yield long term benefits to the company and society at large. It is important that brands which practice sustainable fashion are committed to make sustainability profitable and desirable in the fashion industry. Consumers are attracted always to good designs and fabrics [1].

Being environmental sustainable means having a responsible interaction with the environment to avoid depletion of natural resources and allow for long-term environmental quality. The 
practice of environmental sustainability helps to guarantee that the needs of today's people are met without depleting the need of future generations [2].

Materials are considered to be eco-friendly if they are renewable, and it takes fewer chemicals for production [3]. Garments that can perform multi functions encourage a deeper relationship between wearer and garment. This can be achieved through different fashion solutions. The garments which can be worn for longer periods and on different occasions, minimizes waste generation by decreasing the consumer's need to purchase new garments, and therefore reduce the flow of materials in the fashion industry [4].

Customers depend on new designs to change their clothing style and garments that can be converted offer new designs at a comparatively low price than buying new garments to look different everyday. These garments take up less space and are a perfect alternative for people who prefer less is more. A fad is a clothing or accessory that reaches a peak very soon in the fashion life cycle. Convertible garments are the new fad and the option of affordable clothing and the variety in choices that it offers may help this fad to soon rule the global fashion industry. With respect to those who spend less on clothing, these garments are perfect and environmentally conscious people are glad since garments which can transform will consume less fabric to produce a multi-style garment [5].

Sustainability has become an extensively talked about issue in the apparel industry due to the nature of the industry. Without being sustainable the survival of the apparel industries is becoming increasingly difficult [6]. The fashion industry has a damaging impact on the environment. And after the oil industry it ranks second in polluting the world. The environmental damage only increases as the industry grows [7]. Innovative ideas are a hallmark of good fashion designers and textile brands. People were made fun of when they made the mistake of wearing their clothes on the wrong side. The clothing that showed up with rough edges, faded prints and untidy look were not liked. Designers and fashion houses have worked on the concept of reversible garments and today, reversible apparels are in trend. Convertible clothing is similar to the concept of reversible apparels. With not very high budgets, customers prefer garments which cost less as well as serve different purpose. One garment which can be perfect for work or a casual wear is what customers look for. At first, this idea was thought to be someone's imagination, but gradually it turned into reality. Convertible clothing is still a new idea, but consumers have started to look forward to it [8].

There are many brands that use plastics and other fabrics that damage the environment. For example, lot of polyester fiber used in our clothes end up in landfills. Conversely, a company which is eco-friendly uses fibers such as hemp, organic cotton, recycled cotton, and materials from recycled bottles, and other low water usage materials such as Pinatex and Tencel for example. Due to recent advancements in materials, now we see plastics being replaced with biodegradable alternatives [1].

Based on the above literature, this paper deals with consumer's intention towards purchasing sustainable clothing and design and development of women's convertible clothing collection. 


\section{Materials and Methods}

\subsection{Research and Observation}

Online brand research: Online brand research is done by visiting websites of various brands like twee in one, Fab India, Seams friendly, House of primes, Season, Encircled, Avesso, Swak designs, Patagonia, HFS collective and Tanya health. By researching these websites, knowledge about their styles, trend, process, design and print detailing and techniques were known.

Fashion websites: Fashion websites helps to gather recent news from various brands and also makes one aware of the recent changes and problems in the fashion industry. Websites Like fibre2fashion, common objective, green strategy, textile focus were some of the websites used for knowing recent news.

Government websites: Government agencies like mygov.in were also referred for government related policies and actions. After researching the fashion websites, online brand research, government websites and books it was noticed that brands have started to produce transformable clothing.

\subsection{Design development}

Concept: Convertible clothing provides consumers with creative and innovative approaches to demonstrate their individuality. It also meets consumers' fashion demand while not requiring more purchases. This feature of convertible apparel would appeal to those consumers who wish to obtain unique and creative fashion styles without relying on frequent purchases of new items.

Designer boards: After deciding on the concept of convertible clothing designer boards like mood board, colour board, story board and fabric board were developed.

Design collection: After developing the designer boards, a collection was made with eco friendly materials like recycled cotton, tencel and hand-woven cotton fabrics. Seven designs were developed.

\subsection{Product development}

Product development stage is the final stage where the products were stitched and developed as per the specifications of the design. The products were developed with multifunctional aspect.

\subsection{Survey}

After design development, a survey was conducted in which a questionnaire was made to evaluate the consumer's perception on convertible clothing. The factors used in the questionnaire are colour, fabric selection, silhouette, convertibility factor and overall design.

Another survey was conducted in which a questionnaire was made to record consumer's intention to buy sustainable clothing. The questions used for survey were as follows.

Do they prefer sustainable clothing?

Will they prefer convertible clothing style (one garment, two or three ways)

Will they make significant effort to their lifestyle to lesser environmental impact? 
Are they willing to recycle their clothes?

Will they buy recycled garments?

Items they are willing to cut spending on?

Will they be throwing out fashion items less often?

Will they intend to buy more second-hand clothing?

Will they intend to buy up cycled garments?

Will they be repairing fashion items than throwing?

\section{Results and Discussion}

\subsection{Design development}

1) Mood board and Story board: This mood depicts joy and happiness that arises with the hope that all our things will come back to normal after the pandemic. This story board gives hope that all our activities will resume and come back to normal (Figure 1).

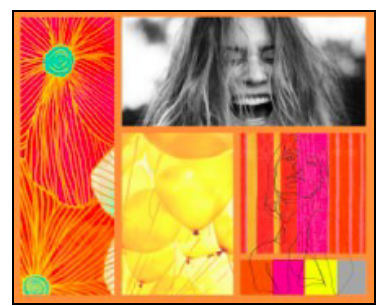

(a)

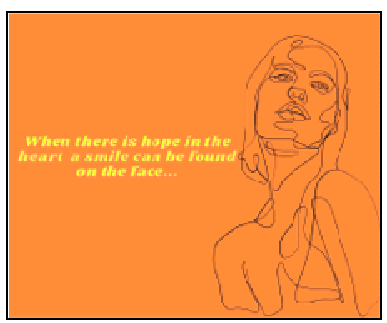

(b)

Fig. 1. (a) Mood Board and (b) Story Board

2) Colour board and Fabric Board: The colours used here are orange, yellow, pink and neutral shades. These colours are the colours of joy and happiness. The fabrics used here are tencel, handwoven cotton and recycled cotton fabrics. These fabrics are biodegradable, ecofriendly, and are also woven under temperature-controlled atmosphere with thermocol insulated buildings where even electricity is reduced to half as there is no need for fan (Figure 2). 


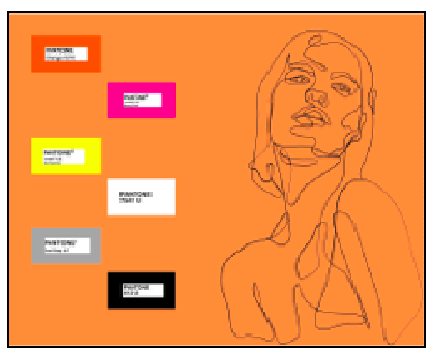

(a)

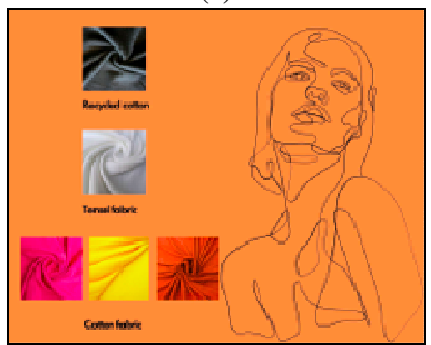

(b)

Fig. 2. (a) Colour Board and (b) Fabric Board

\subsection{Design and product development}

3) Four way clothing: This garment (Figure 3) can be worn in 4 ways. It can be worn as a dress or as a short top or as a skirt or as a full jacket. This change in clothing style is done with the help of the zipper alone. This garment can be teamed up with any combination of top and bottom. 


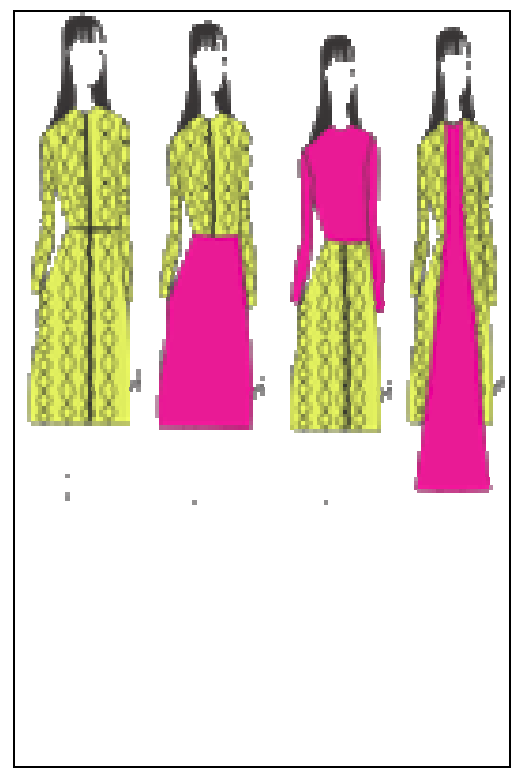

(a)

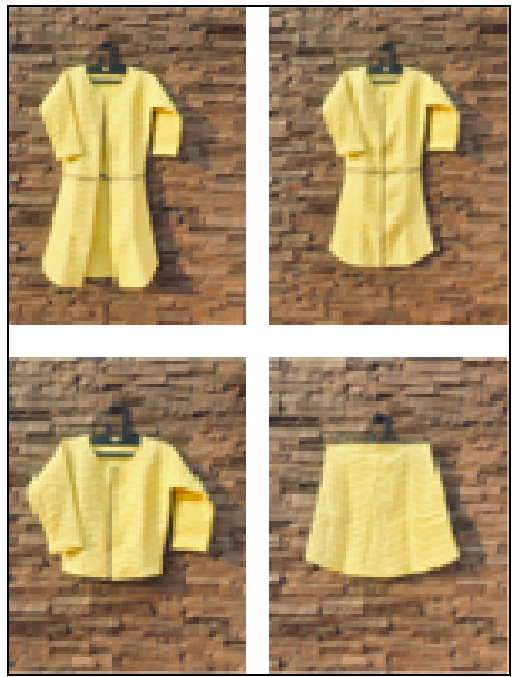

(b)

Fig. 3. Four way clothing (a) Designs and (b) Garments

4) Two way convertibles: This garment (Figure 4) can be worn in two ways. It can be worn either as a shorts or a pant. The con=version of style can be done by using a zipper. The top can be 
worn in two ways with either a $\mathrm{V}$ neck or a $\mathrm{U}$ neck.

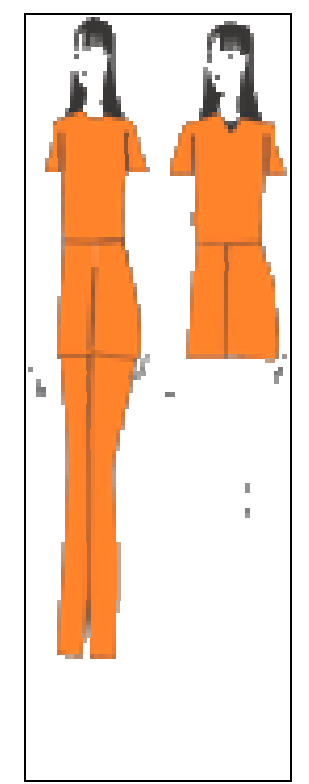

(a)

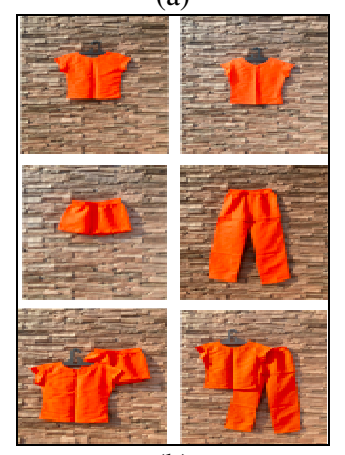

(b)

Fig. 4. Two way convertibles (a) Designs and (b) Garments

5) Length adjustable clothing: This is a style where length of the dress can be adjusted (Figure 5). The length of the dress can be adjusted using buttons. 


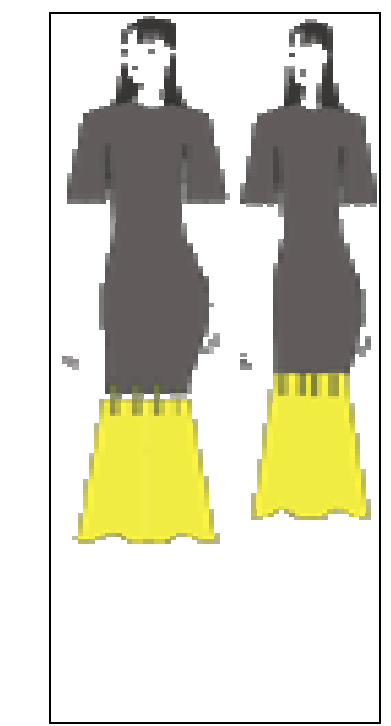

(a)

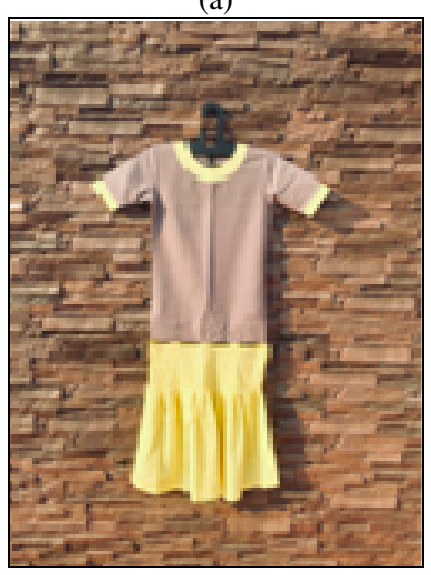

(b)

Fig. 5. Length adjustable clothing (a) Designs and (b) Garments

6) Reversible clothing: This is a reversible garment (Figure 6). It can be worn both sides with different colour combinations. 


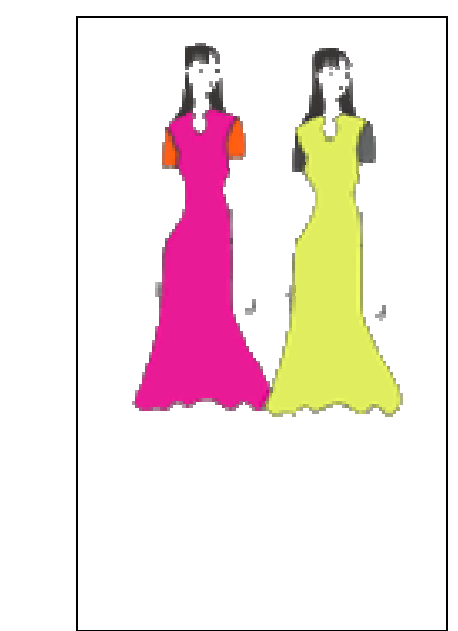

(a)

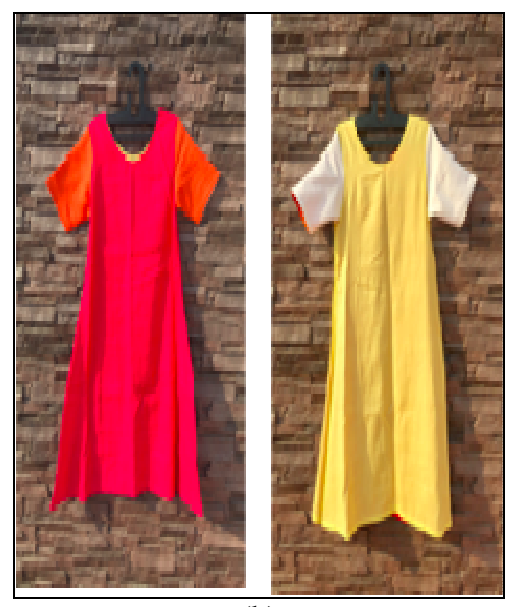

(b)

Fig. 6. Reversible clothing (a) Designs and (b) Garments

7) Waistcoat to tote bag: This is a waistcoat (Figure 7) which can be converted into a tote bag. This conversion can be done using zippers and buttons. 


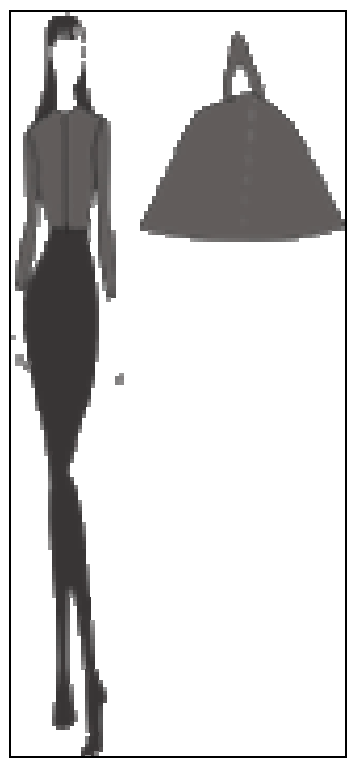

(a)

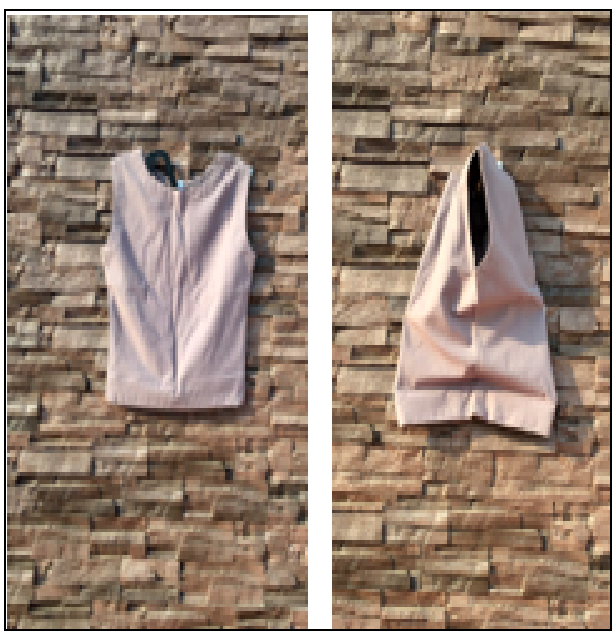

(b)

Fig. 7. Waistcoat to tote bag (a) Designs and (b) Garments

8) Cape to gown: This is a short dress (Figure 8) which can turn into a full gown after removing the buttons. The gown can be worn with cape or without cape. 


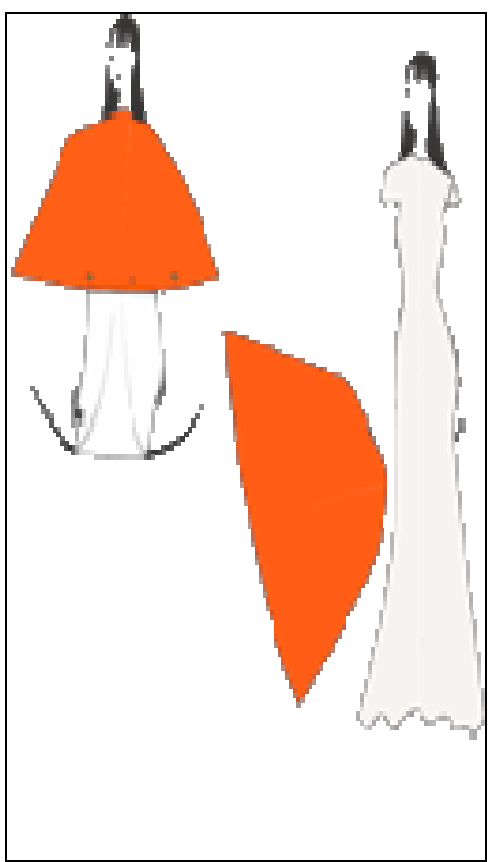

(a)

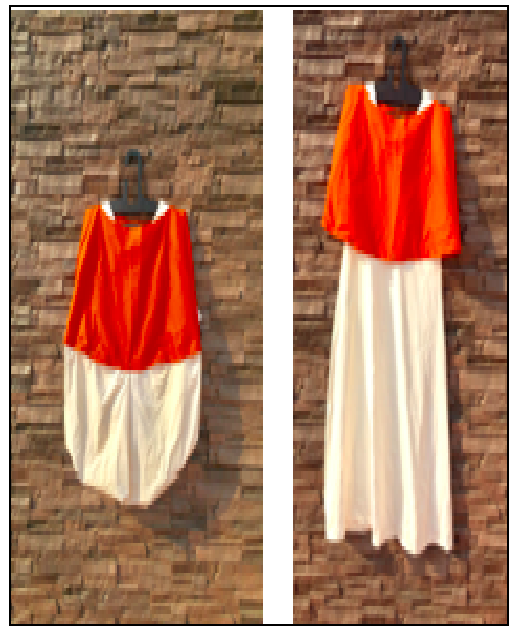

(b)

Fig. 8. Cape to gown (a) Designs and (b) Garments

9) Scarf to mask: This is a fashion accessory (Figure 9) which can be worn as a mask or it can also be worn as a scarf. This is the need of the hour as masks are going to be inbuilt in our 
wardrobe for some time to come.

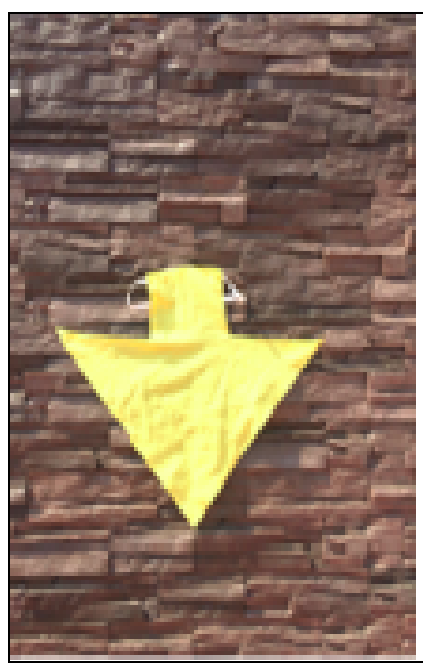

(a)

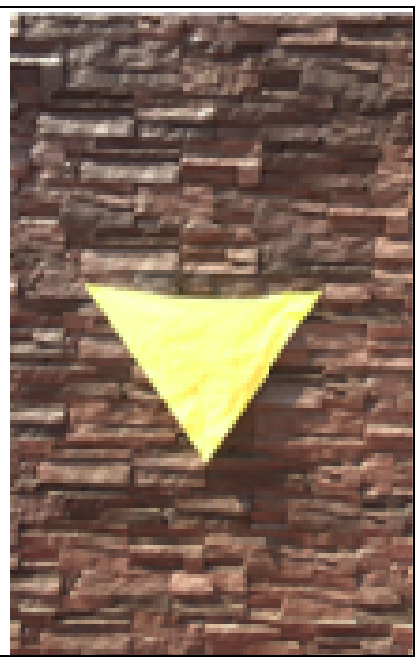

(b)

Fig. 9. (a) Mask and (b) Scarf

\section{Survey results}

In order to test the perception of the consumers with respect to the designs created, a survey was conducted with respondents from Tamil Nadu. The designs which are shown in Figure 5 and 6 , namely length adjustable clothing and reversible clothing has got the highest rating. Also, in order to record consumer's intention towards sustainable clothing, a survey was conducted with respondents from Tamil Nadu. The results showed that people prefer sustainable ways in clothing and that it is going to be the future of fashion.

\section{Conclusion}

Today a lot of fashion industries around the world are facing harsh environmental and social implications. The purpose of this study was to develop a convertible clothing collection using ecofriendly textiles like tencel, and handwoven fabrics. This study has explored various innovative techniques that are taking place in the fashion industry with respect to sustainability issues in dealing with garments' shelf-life. Consumer awareness towards sustainability has shown a great progress in the recent years. People are willing to buy sustainable fashioned goods and are slowly adopting slow fashion and sustainable practices. Garments are bought, worn and thrown away which increases the amount of waste. Most of the garments are thrown into the landfill, so in order 
to reduce the amount of waste government and other organizations are implementing various methods to prevent the textile wastes like take back schemes and reuse or resell platforms. It also causes climatic change. One of the methods to reduce waste is convertible clothing which not only reduces the waste but also reduces the production of garments. It's tough to say if convertible clothing will be the next frontier, but it's definitely a necessary step in the business of fashion. Convertible clothing will not only give variety in clothing but it will also reduce the consumption of clothing, thereby reaching towards sustainable goals. An effort to make seven convertible clothing designs was made, and further research can also take place in this area. The concept of versatility or convertibility is a new idea and consumers might gain the satisfaction of buying and using something versatile. So, if it is accepted and loved by majority of the people, then yes, convertible clothing truly will be the next frontier in environmentally responsible clothing.

\section{References}

[1] Available: https://www.fibre2fashion.com/industry-article/7238/ ethical-and-sustainable-fashion

[2] Available: https://study.com/academy/lesson/environmental- sustainability-definition-andapplication.html

[3] R. Antony, pp. 67-73.

[4] Available: https://www.fibre2fashion.com/industry-article/7593/ convertible-clothing-getting-rid-offashion-stereotypes, H. Koo, 2012.

[5] Available: http://textilefocus.com/sustainability-textile- industry-reality-challenges/

[6] Available: https://www.sustainyourstyle.org/old-environmental- impacts

[7] Available: https://www.fibre2fashion.com/industry-article/7593/ convertible-clothing-getting-rid-offashion-stereotyp 